\title{
DENTAL NURSES CAN TRAIN ONLINE
}

The Dental Nurse Education and Training Centre at King's College Hospital NHS Foundation Trust has launched the first fully supported online course leading to the National Examining Board for Dental Nurses (NEBDN) National Certificate.

The course has been built

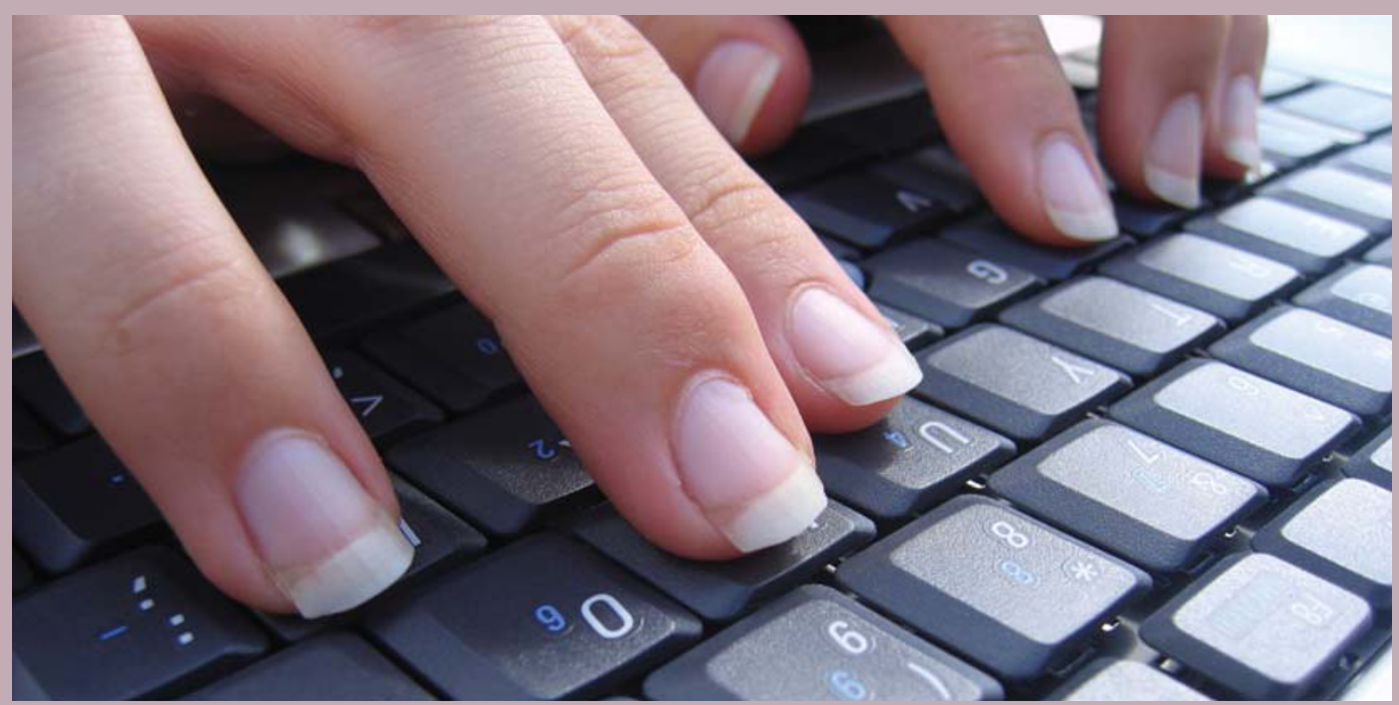
in a modular format using

the Moodle platform and each module consists of a presentation, online and offline activities, quizzes and a summative assessment.

Student support is available from qualified and experienced dental nurse tutors via online forums, email, instant messaging, Skype, webcam chats and telephone. Work- place support is provided by nominated mentors (a prerequisite for acceptance on the course) and an Online Mentor Support course is provided, alongside the National Certificate course, to facilitate this process. The course consists of three face-to-face days, induction and two mock examinations, which are provided regionally.

It is open to anyone employed as a dental nurse wishing to qualify via the NEBDN

National Certificate who is able to identify a willing mentor in the workplace. For further information visit www.kch.nhs.uk/dnetc or call the office administrator on 02032991611.

\section{DENTAL NURSE RECEIVES ACCOLADE}

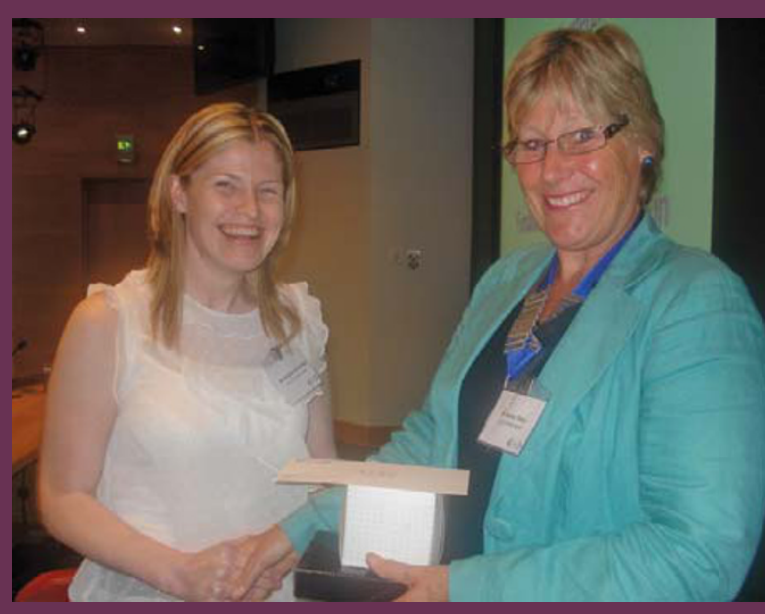

Michelle Woolridge was recently awarded by The Society of Advancement in Anaesthesiology in Dentistry (SAAD) at their annual conference in London for gaining the highest mark in the country for the March 2008 NEBDN sedation examination at distinction level.

Having worked in the dental industry since she was 16-years-old, she left in 2005 to become a police officer, but returned to dentistry two and a half years later.

Michelle, who currently works at the Queensway Dental Practice in Billingham as a dental nurse commented, 'I felt very proud to receive the award and it reinforced to me how special my return to NHS dentistry has been and how much I now look forward to going to work. It is more like a great hobby than work!'

\section{DENTAL TECHNOLOGY} INDUSTRY

\section{CELEBRATES}

ACHIEVEMENTS

I The Dental Laboratories Association's

I 2009 Chairman's Dinner this year fea-

tured the presentation of awards for

dental technology professionals and those

I still in training. It was presented by Dominic

I Holland of Never Mind the Buzzcocks and Whose

Line is it Anyway? fame.

At the DLA Chairman's Dinner and

I Awards Ceremony, incoming Chairman

I Jonathan Bill recognised achievements

I in a number of categories. Amongst the

I awards of the evening was Dental Tech-

nology Student of the Year, awarded

I to Michelle Pillinger; Dental Tech-

I nician of the Year, awarded to

Gemma Lynch;

whilst the

Outstanding

- Contribu-

I tion Award

I went to

I Graham

Findlay.
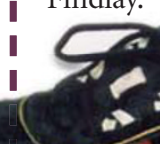

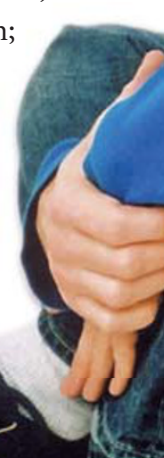
1525

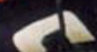

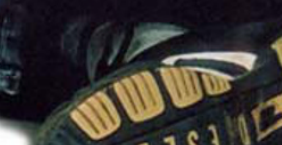

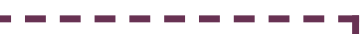

